\title{
El segundo libro: Cuentos de circunstancias de Julio Ramón Ribeyro
}

Resumen

En este artículo el autor realiza un análisis de los pequeños mundos narrativos que creó Julio Ramón Ribeyro (1929-1994) en sus innumerables cuentos, específicamente de su segundo libro titulado Cuentos de circunstancias (1958). Mediante esta lectura se reconocerá los recursos iniciales del estilo de quien llegaría a convertirse en uno de los principales creadores de mundos verbales imaginarios de la literatura narrativa peruana del siglo XX.

Palabras clave: Ribeyro, mundos narrativos, literatura peruana

Abstract:

In this article, the author develops an analysis of the small narrative worlds created by Julio Ramon Ribeyro (1929 - 1994) in his innumerable stories, specifically in his second book entitled Stories of Circumstances (Cuentos de circunstancias, 1958). By reading this story we will identify the initial style resources of someone who would become one of the principal creators of imaginary verbal worlds of the Peruvian narrative literature in the twentieth century.

Key words: Ribeyro, narrative worlds, Peruvian literature

1 segundo libro de relatos que publicó Julio Ramón Ribeyro se denomina Cuentos de
circunstancias y está constituido por doce textos, dos más que los del primer volumen de 1955. Si comparamos la edición original con la de los cuentos completos que empleamos en esta investigación y en la que se reproduce el conjunto de las piezas narrativas que integran 
el volumen, descubrimos algunas pequeñas diferencias que pasamos a señalar. En primer lugar, la obra de $1958^{1}$ reúne un total de diez cuentos, mientras que la de 1994 nos entrega doce. Los que se incorporan en esta última son «El libro en blanco» y «La molicie». En segundo lugar, en cuanto al orden en que aparecen los textos se notan algunas variaciones, la principal de las cuales es que los dos relatos incorporados en la edición de 1994 aparecen después de «Doblaje» y antes de «La botella de chicha». Igualmente, en la edición príncipe, el penúltimo es «El tonel de aceite» y el último, «Los merengues»; en cambio, en la más reciente, este último es el penúltimo y aquél, el último. En tercer lugar, el volumen de los cuentos completos ofrece al final de cada texto la fecha de escritura de este; ello nos permite comprobar que «El libro en blanco» se escribió en 1993 en París, es decir, treinta y cinco años después de la aparición del segundo libro del autor; a su vez, «La molicie» nació en Madrid en 1953 y, por lo tanto, pudo haber aparecido en la edición de 1958, pero no ocurrió así.

Antes de ingresar al análisis de cada uno de los relatos, cabe realizar algunas observaciones más. La primera es que Cuentos de circunstancias carece de prólogo, y por tanto el lector ingresa de frente al mundo que nos propone Ribeyro en sus ficciones, sin ninguna advertencia o apreciación que haya que tomar en cuenta. Por otra parte, todos los textos de Los gallinazos sin plumas (1955) presentan una uniformidad y homogeneidad en cuanto a la elección de un narrador heterodiegético y omnisciente que emplea siempre la tercera persona y recrea una realidad cuyas características señala el autor en el prólogo. En cambio, en Cuentos de circunstancias (1958), el narrador es, en unos textos, un autodiegético (Cf. Reis y Lopes 1995: 158), que utiliza la primera persona, y en otros, un heterodiegético (1995: 160) que cuenta en tercera persona. También se constata la existencia del homodiegético (1995: 161), es decir, el narrador testigo en primera persona.

En cuanto a lo que Mario Vargas Llosa denomina el nivel de realidad (1997:107) presente en los textos del primero y del segundo libro de Julio Ramón Ribeyro, es destacable la diferencia entre el realismo o neorrealismo que caracteriza a todos los cuentos de Los gallinazos sin plumas (1955) y la alternancia entre el realismo y la fantasía ${ }^{2}$ que es posible

1 Nos referimos a Julio Ramón Ribeyro. Cuentos de circunstancias. Lima: Editorial Nuevos Rumbos, 1958, 96 pp. Esta edición contiene los siguientes cuentos: «La insignia», «El banquete», «Doblaje», «La botella de chicha», «Explicaciones a un cabo de servicio», «Página de un diario», «Los eucaliptos», «Scorpio», «El tonel de aceite», «Los merengues».

2 Al hablar de su producción fantástica, Ribeyro dice: «En realidad no estoy muy seguro de haber escrito 
descubrir en los doce textos que forman parte de Cuentos de circunstancias (1958). Las razones de esta diferencia no obedecen a una posible evolución que habría experimentado el escritor en el breve lapso de tres años, sino al hecho de que el volumen de 1955 supuso una selección de un punto de vista realista o neorrealista, lo que llevó a que en esta obra se dejara de lado todo aquel texto que no coincidiera con la propuesta estético-ideológica que en ese momento sostenía el autor.

Y dicha evidencia, que está expuesta en el prólogo del primer libro, se reafirma si se revisa las fechas de escritura de cada texto, que se consignan en la edición de los cuentos completos. En efecto, comprobamos que los ocho relatos de Los gallinazos sin plumas se escribieron en el lapso de dos años (de 1953 a 1954) y todos ellos en Europa (siete en París y uno en Madrid). Las ficciones que se incluyeron en Cuentos de circunstancias se pergeñaron unos en Lima, otros en Europa, y algunas son más antiguas que las que se escogieron para el volumen de 1955; lo cual quiere decir que el criterio del autor no respondía a lo cronológico, sino a lo temático, y esta preferencia tenía que ver con sus opciones en tanto escritor peruano de la década del 50.

\section{El marrador realista heterodiegético}

C omo el libro de 1958 es más abierto que el primero de 1955, tanto en el nivel de realidad al que alude como en el tipo de narrador empleado, el lector puede intentar una suerte de caracterización del volumen tomando en cuenta los dos criterios que acaban de mencionarse (subrayados con negrita).

Este punto de vista nos permitirá apreciar las relaciones de semejanza y de diferencia que hay entre el primer y el segundo libro de cuentos de Ribeyro. Así, comprobamos que en Cuentos de circunstancias nos volvemos a encontrar con un narrador realista heterodiegético que está presente en cuatro textos, lo cual constituye un $40 \%$ del total de relatos, si consideramos la edición príncipe de 1958 (con 10 ficciones), y 30\%, si nos guiamos por el volumen de los cuentos completos de 1994 (con 12). En ambos casos, este grupo posee una cierta representatividad nada desdeñable como veremos al acercarnos a ellos.

cuentos fantásticos. Entiendo por cuento fantástico un cuento que es puro producto de la imaginación, en el cual las referencias a la realidad son escasas. En cambio, mis cuentos que son considerados fantásticos están apoyados siempre en hechos reales que he conocido o vivido, pero en los cuales hay siempre un momento en que la historia se dispara un poco hacia lo insólito o inesperado. No es el cuento fantástico típico, se trata de un cuento realista que patina o se desliza de pronto en otra dimensión, la dimensión de lo insólito». En «El asedio de la fama». Entrevista de Mito Tumi (Cf. Ribeyro 1998:293). 
Pertenecen a este conjunto: «El banquete», «Scorpio», «Los merengues», «El tonel de aceite». Todos ellos son pasibles de ser considerados como realistas, aunque como se verificará, el realismo de estos textos difiere en varios aspectos del de 1955. Un primer aspecto, por ejemplo, es que de los cuatro relatos, tres se desarrollan en el mundo urbano (que podría ser Lima), pero dicho mundo no es exclusivamente el de la marginalidad; por el contrario, predominan aquellos en los que el ambiente corresponde al universo de la clase media más o menos acomodada (dos relatos), y solo uno de ellos («Los merengues») muestra espacios equiparables a los que aparecen en el libro de 1955.

Por otro lado, en uno de los relatos («El tonel de aceite») la historia transcurre en el mundo rural y con los indicios que ofrece el texto cabe plantear que estamos en un espacio andino o próximo a este. Desde esta perspectiva el citado texto sería uno de los primeros en los que Ribeyro se aventura a recrear narrativamente un mundo que en tanto ser humano y escritor no le es tan familiar como el de Lima. Ello no impidió que en un buen número de relatos, el autor plasme historias desarrolladas en el ámbito de la región de la Sierra (urbana o rural). ${ }^{3}$

En cuanto al tipo de realismo que predomina en los textos, cabe resaltar el propósito del escritor de recrear cada una de las historias con un máximo de verosimilitud, de modo que permitan al lector hacerse una idea aproximada del mundo al que se refieren. Y como hemos indicado, aunque no hay denominaciones sobre los lugares en que ocurren los hechos, si se sugiere que corresponden a espacios de la ciudad de Lima.

Por ejemplo, en «El banquete» (cf. González Montes 2005: 99-103), toda la historia transcurre en ciertos ambientes de la ciudad capital y de manera especial, los sucesos se concentran en la residencia del protagonista, cuyo nombre tiene un matiz irónico: Fernando Pasamano. Este personaje, que ha alcanzado una situación económica bastante holgada, es de origen provinciano y tiene lazos de parentesco no muy cercanos con el Presidente de la República de la época en que ocurren los hechos.

Fernando Pasamano planea aprovechar el vínculo familiar con el fin de incrementar su fortuna y mejorar su status social y para ello decide organizar un banquete en su residencia e invitar al Presidente. Su idea consiste en pedirle a este que lo mande de embajador a algún

3 En su libro Tres historias sublevantes (1964) incluyó un relato por cada una de las tres regiones geográficas que tiene el Perú. El que corresponde a la Sierra es «El chaco». 
país europeo y que autorice la construcción de una vía férrea que pase cerca de una de las haciendas del anfitrión.

La organización del banquete representa para Pasamano el desembolso de una gran cantidad de dinero, pero él considera que este fuerte egreso es una inversión razonable pues si el Presidente accede a una de sus peticiones podrá recuperar con creces lo que ha gastado. En efecto, luego de los costosos y detallados preparativos, el banquete se realiza y el anfitrión consigue hacer la petición a su encumbrado pariente, y este le manifiesta que le concederá lo que ha solicitado. Pero el desenlace es funesto para Pasamano pues al día siguiente de la comilona presidencial, el mandatario sufre un golpe de estado que frustra totalmente las esperanzas del anfitrión.

En este relato el narrador muestra una mirada crítica e irónica sobre el personaje, y a través de la historia que este protagoniza se permite cuestionar la actitud oportunista y arribista del mismo, que quiere obtener ventajas valiéndose no de su trabajo sino de sus vínculos familiares con quien detenta el poder. A propósito del poder, «El banquete» debe ser uno de los primeros relatos en los que Ribeyro desarrolla el tema de la política, vinculada a un tópico que retomará más adelante en su novela Cambio de guardia (1975), publicada en plena época del gobierno militar de Velasco Alvarado.

Nos referimos al tópico del golpe militar como rasgo característico de la política peruana durante gran parte del siglo XX. De modo que su utilización en «El banquete» es perfectamente verosímil en nuestro contexto, y de paso constituye una sanción tanto para el presidente que acepta conceder favores por razones familiares, como para el pariente que considera que el Estado debe estar al servicio de los intereses particulares de los allegados al poder.

Otro relato que también se recrea desde la perspectiva de un narrador heterodiegético en tercera persona, es «Scorpio» (Cf. Gonzáles Montes 2005: 144-148), que enfrenta a dos adolescentes que son hermanos y ambos aficionados a la captura y posesión de pequeños y peligrosos animales (arañas y escorpiones). Precisamente, el cuento mencionado alude a que los dos han peleado por la posesión de un escorpión, capturado por Ramón, el hermano menor, y arrebatado a este por Tobías, el hermano mayor. A partir de esta situación de desventaja para Ramón, el narrador omnisciente sigue a este en sus planes para vengarse de la desposesión del escorpión que ha sufrido a manos de su hermano.

El relato no tiene el propósito de ilustrar un conflicto de naturaleza social, sino el de mostrar los enfrentamientos que se producen entre personajes que son de una misma 
familia, pero que por razones de edad o de temperamento luchan entre sí para afirmar su personalidad o su ego, en un mundo donde las relaciones se basan en el conflicto físico o psicológico permanente. Por esa razón, «Scorpio» es un relato realista y verosímil pues presenta una situación que suele darse entre hermanos, en especial cuando están en la etapa de la adolescencia. Desde el punto de vista social, los personajes no son marginales ni pobres; pertenecen a una clase media de moderados recursos.

«Los merengues» (Cf. Gonzáles Montes 2005: 148-152) también es contado por un narrador de características similares al de «Scorpio» y el protagonista, asimismo, es un niño, en este caso de extracción popular, ${ }^{4}$ que vive en el barrio miraflorino de Santa Cruz, donde conviven familias que pertenecen a estratos diferentes. El niño, que tiene el sobrenombre de «Perico», no se enfrenta a otros niños sino al mundo adulto. Y ello ocurre porque desea comprar en una pastelería cercana a su casa unos dulces denominados «merengues», por los que siente especial predilección.

Para poder realizar la adquisición de sus dulces favoritos, «Perico» comete un pequeño «delito»: sustrae parte del dinero que su madre guarda en un lugar de la cocina. Aprovechando que esta ha salido al trabajo, el niño consuma el pequeño hurto y luego se dirige a la pastelería para realizar la compra de la golosina con la cual ha soñado muchas veces. Lo singular es que llega hasta el lugar y solicita al vendedor que le proporcione los merengues a cambio del dinero que muestra en sus manos.

Pero el vendedor considerando que los veinte soles son una suma exagerada para adquirir merengues le niega a Perico el derecho de convertirse en comprador y lo conmina a abandonar la tienda. El frustrado niño tiene que abandonar la tienda y su venganza consiste en tirar las monedas una a una y soñar con un tiempo futuro en el que pueda comprar lo que se le antoje.

En este relato, además de la anécdota de la frustrada compra de los merengues, el narrador incluye algunos elementos que permiten apreciar el nivel socio-económico al que pertenece Perico. Este personaje es de extracción popular, como hemos señalado, y en ese sentido se parece en alguna medida a los niños que aparecen en "Los gallinazos sin plumas». Y con respecto a la sustracción del dinero que realiza «Perico», no hay de parte del narrador una censura, sino una mirada irónica y comprensible.

4 Sobre la presencia de niños y adolescentes en los relatos de Ribeyro, se puede consultar un interesante artículo del escritor peruano Jorge Eslava (1993: 32). 
En el relato «El tonel de aceite» vuelve a enseñorearse la figura de un narrador heterodiegético en tercera persona, que conduce el desarrollo de la historia con total dominio de los sucesos, espacios y personajes. Estamos ante un típico cuento "fragmento" que muestra un momento crucial en la vida de un número breve de personajes y que se resuelve a través de una autosanción a aquél que ha perpetrado un delito mayor: el asesinato de un hombre por motivos sentimentales.

Quien ha cometido homicidio es Pascual, y en su afán de escapar a la justicia ha huido del lugar del crimen y se ha refugiado en la casa de su tía Dorotea, una mujer ya mayor, de rasgos indígenas y que vive en una zona semirural. El relato nos muestra a Pascual en casa de su tía, y los dos momentos extremos de su situación se pueden definir con dos adjetivos: escondido y ahogado. Lo que implica pasar de la vida a la muerte, y por tanto significa un final catastrófico para el protagonista.

Y ello ha ocurrido porque los policías llegan hasta el lugar donde está escondido Pascual; pero antes de que toquen la puerta, dialoguen con Dorotea y esta los autorice a entrar en la casa y verificar si está o no el homicida (la mujer dice que no lo ha visto), ella le ha ordenado a Pascual que se introduzca en un gran tonel de aceite que se ubica cerca de la puerta. El perseguido obedeció y por ello cuando los policías ingresan y lo buscan no lo encuentran pues Pascual está dentro del tonel. Incluso uno de ellos golpea al recipiente y anuncia que volverá para que Dorotea le obsequie aceite.

Después de que los policías se marchan, el ambiente de la casa queda en paz y sin la tensión y el suspenso que generaron la presencia de los perseguidores, pero Pascual se ha ahogado con el aceite y ha muerto, según lo sugiere el narrador y con esta insinuación concluye el relato. No puede decirse que hay una moraleja o un propósito didáctico en la historia. Lo que se quiere contar es una anécdota donde están presentes, como se ha señalado, el suspenso y la tensión, por el enfrentamiento entre alguien que se ha puesto al margen de la ley (ha asesinado a un hombre) y unos policías que lo persiguen en nombre de la ley. Y con ello, el escritor muestra un aspecto de la realidad desde un punto de vista realista y equilibrado, aunque haya de por medio dos muertes: la del asesinado y la del propio homicida.

\section{El narrador realista autodiegético}

Bjo esta denominación agrupamos a aquellos relatos que tienen como narrador a una
voz en primera persona, que además ha participado en el desarrollo de la historia en 
calidad de protagonista o de personaje importante; por ello se le llama narrador personaje y en la terminología narratológica se le identifica como el autodiegético, porque cuenta algo acerca de sí mismo (Cf. Reis y Lopes 1995: 158).

Como el narrador es un personaje que se asemeja en parte significativa al Julio Ramón real en la época de su adolescencia o juventud, según las versiones biográficas o autobiográficas que manejan los lectores o críticos, algunos de estos últimos llaman a estos relatos autobiográficos, por su relación con pasajes de la vida real del ser humano que concibió los cuentos, pero esto siempre es relativo (Cf. Reis y Lopes 1995: 158). Aun cuando estos relatos se basaran o tuvieran como materia prima experiencias que vivió el escritor real, lo pertinente desde el punto de vista del análisis literario es la ficcionalización llevada a cabo y el producto final, su capacidad de persuasión, su trascendencia, como sin duda ocurre con los textos creados por Ribeyro.

Son, pues, relatos de este tipo: «La molicie», «La botella de chicha», «Explicaciones a un cabo de servicio», «Página de un diario» $\mathrm{y}$ "Los eucaliptos». ${ }^{5}$ De estos cinco, tres tienen como protagonistas a personajes que evocan a la figura del propio escritor en su calidad de vecino de la ciudad de Lima en la que vivió desde su nacimiento hasta la década del 50 en que comienza su etapa de viajero. Por ello en "La botella de chicha», "Página de un diario» y «Los eucaliptos», las historias se basan en la evocación de sucesos vividos en la época de la adolescencia y de la juventud del protagonista.

Lo peculiar de «Página de un diario» (Cf. González Montes 2005: 135) es que el narrador recuerda con pesadumbre el día en que murió su padre y todo lo que ello implicó en ese terrible momento y en su futura vida. Estamos frente a un cuento fragmento, pues los hechos transcurren entre el momento del deceso y unas horas del día siguiente. El protagonista rememora lo difícil que fue para él tomar conciencia de que su padre ya no era una persona sino una cosa, a la que podía mirar como tal en el ataúd.

Pero el relato muestra también el modo en que el joven deudo superó el trauma de la pérdida de su padre a una edad tan temprana. Ello ocurrió cuando el protagonista recorriendo la casa ${ }^{6}$ en esas horas de dolor y soledad, llegó hasta la habitación donde estaba

5 Véase el análisis que hacemos de cada uno de ellos en nuestro ya citado estudio (Cf. González Montes 2005: 120 y sgts.).

6 Dice Minardi Giovanna que «En "Página de un diario” [...] domina el espacio de la casa como cuna de nuestra existencia» (2002: 101). Pero también puede ser el lugar donde concluye la vida, como se observa en el relato. 
el escritorio de su padre. Se acercó hasta el mueble y ubicó allí el lapicero de pluma fuente que utilizaba su progenitor y que era el símbolo de su autoridad.

Identificado el objeto predilecto, el narrador se lo apropia material y simbólicamente y piensa que puede llevarlo consigo, pues «ihasta tenía grabadas las mismas iniciales!». El proceso de apropiación se consuma cuando con dicha pluma fuente traza su nombre, «que era también el nombre de mi padre». ${ }^{7}$ Y esa experiencia lo lleva a comprender que su padre no había muerto, «que algo suyo quedaba vivo en aquella habitación». Y se verifica, también, en la mente del huérfano el nacer de un sentimiento de identificación: «Pero si yo soy mi padre» (Cf. González Montes 2005: 136).

El relato «Los eucaliptos» es otro notable texto evocativo sobre sucesos vividos por el narrador en el distrito limeño de Miraflores, entrańable mundo asociado a la adolescencia y que es recreado desde una distancia temporal de 20 años (tiempo de la escritura). Como lo hemos analizado exhaustivamente (Cf. González Montes 2005: 138 y sgts) remitimos a esas páginas y solo queremos puntualizar que este cuento está vinculado al proceso de modernización urbana que sufre el barrio en que vive el protagonista. Este rápido e irreversible proceso de cambios trae consigo la desaparición de todos aquellos elementos que eran parte del entorno tradicional en que discurría la vida apacible del narrador y de sus amigos. Entre esos elementos arrasados por el progreso están los eucaliptos que daban sombra y acompañaban a los jóvenes. ${ }^{8}$

Cierra el trío de relatos evocativos del mundo de la adolescencia en el contexto miraflorino, el cuento «La botella de chicha», también uno de los clásicos del maestro Julio Ramón. El narrador recrea una curiosa anécdota, no exenta de humor, que le ocurrió en su época de universitario, cuando urgido por la necesidad de contar con algo de dinero y descartar la opción de pedírselo a alguien de su familia, decidió extraer de la despensa de su casa una botella de chicha que se guardaba para una ocasión especial.

A partir de esa situación inicial de insolvencia económica del protagonista se van generando otras como producto del azar y conducen a un desarrollo y desenlace contrarios a los propósitos específicos de aquél, pues no consigue el dinero que necesita y la famosa chicha es reemplazada por un vinagre desagradable, pero pese a ello, los miembros de la

7 Sobre la importancia del tema del nombre en la narrativa de César Vallejo, véase nuestro artículo «La narrativa de Vallejo» (González Vigil, ed. 1993: 241 y sgts).

8 Este texto ha sido estudiado por distinguidos especialistas en la cuentística de Ribeyro: Minardi 2002: 102 y Elmore 2002: 66. 
familia la beben creyendo que es la bebida auténtica, y, en cambio, esta última es echada al piso por el padre del protagonista, quien es víctima de un proceso de sugestión que el relato muestra de modo admirable. ${ }^{9}$

En cuanto a los relatos "La molicie» y "Explicaciones a un cabo de servicios», pese a estar construidos por un narrador autodiegético presentan algunas características de contenido o de técnica narrativa que es pertinente destacar para comprobar que aunque Ribeyro no es proclive a grandes cambios en su oficio de cuentista, sí introduce algunos pocos que son indicios del camino que seguirá en sus siguientes libros.

Por ejemplo, «La molicie» no es novedoso en cuanto al tipo de narrador, pero sí lo es respecto del manejo de la atmósfera y del espacio en que ocurren los insólitos sucesos. La acción gira alrededor del curioso enfrentamiento de dos personajes, uno de los cuales es el narrador, contra la fuerza de la naturaleza, identificada con el calor que produce en los dos jóvenes un adormecimiento de sus facultades vitales y los condena a una inacción casi total. Como vemos, la historia no es muy nítida y los personajes son difusos, a lo sumo se sabe que son estudiantes cuyas escasas energías se agotan en esa lucha impersonal contra un enemigo cósmico como es la época de canícula en el verano. Tampoco está identificada el lugar en que los jóvenes soportan el asedio ambiental, pero por los indicios presentes podría decirse que están en una ciudad europea en su temporada veraniega. ${ }^{10}$

En cuanto a «Explicaciones a un cabo de servicio», la novedad está en el sistema narrativo empleado: el narrador, protagonista de los sucesos, no da cuenta de estos a un narratario impersonal y que está fuera del relato en calidad de lector, sino que se dirige a alguien que también está en el mismo nivel de realidad que el narrador: es el policía que lleva detenido y rumbo a la comisaría a Pablo Saldaña, por haber cometido una falta, y mientras cumple su labor de custodio del orden escucha la versión de los hechos que le proporciona Pablo, con el objeto de alegar su inocencia y evitar una futura sanción.

El policía se limita a escuchar el discurso exculpatorio del detenido y no le responde con ninguna palabra, pero conduce con firmeza a Pablo hasta la comisaría y es durante este recorrido que los lectores «escuchamos» también el relato de lo que ha ocurrido: Pablo fue detenido por no haber podido pagar una deuda por los consumos que efectuó en compañía de su amigo Simón Barriga en un restaurante del distrito limeño de Lince. A esta técnica de

9 Véase González Montes 2005: 124 y sgts. Santiago López ha hecho un análisis desde el punto de vista semiótico (1991: 149).

10 Para mayor información véase GonZÁlez Montes 2005: 120 y sgts. 
contar, nosotros la hemos denominado: «el narrador en $1 .{ }^{a}$ y en $2 .^{a}$ persona», pues tiene de ambas (Cf. González Montes 2007: 19): el narrador refiere hechos en los que ha participado como personaje, pero además identifica al receptor y como prueba de ello se dirige a él usando el «tú» o el «usted», y queda claro que este interlocutor no es el narrador que se habla a sí mismo, sino alguien diferente y que también es personaje, como ocurre en este relato, donde es el policía el que acompaña a Pablo Saldaña (Cf. González Montes 2005: 129 y sgts.)

\section{El narrador fantástico y cosmopolita, autodiegético}

Con el mismo tipo de narrador que hemos visto en los relatos comentados, Ribeyro
agrega a su universo cuentístico una nueva dimensión: la del cuento fantástico y cosmopolita a la vez. Ejemplo de ello son «La Insignia», «Doblaje» y «El libro en blanco», pues en cada uno de ellos, un narrador protagonista o coprotagonista nos cuenta sucesos que de una u otra manera pueden ser tipificados como fantásticos y a la vez las acciones se desarrollan en espacios urbanos no identificados o ubicados en ciudades europeas o de otros continentes. En cuanto a la presencia de la fantasía en los relatos del autor, habría que recordar lo que decía este a propósito de su producción no realista: «No es el cuento fantástico típico, se trata de un cuento realista que patina o se desliza de pronto en otra dimensión, la dimensión de lo insólito». ${ }^{11}$

Para comprender la significación profunda de «La insignia» habría que tomar en cuenta dos conceptos: el azar y el absurdo, pues mediante ellos se hace presente lo fantástico, aunque habría que precisar que ambos son también parte de la realidad. En cuanto al azar ${ }^{12}$ es este el que determina que el narrador se encuentre en su camino con «una insignia», se la guarde en el bolsillo y que luego de haberse olvidado de ella la reencuentre y decida lucirla como parte de su atuendo.

A partir de este momento interviene el absurdo, ${ }^{13}$ pues por el solo hecho de lucir dicha insignia, el narrador vive una serie de situaciones insólitas, la primera de las cuales es el ser reconocido como parte de una organización misteriosa a la que ingresa y en la que

11 Véase Ribeyro 1998: 293, nota 22.

12 El Diccionario de la Lengua Española (2001: t 2, 177) define el azar como 'casualidad, caso fortuito'.

13 El DRAE (2001: t 1, 10) define absurdo como 'contrario y opuesto a la razón; que no tiene sentido', 'extravagante, irregular', 'chocante, contradictorio'. 
«hace carrera» y la última es la de haber sido designado presidente de dicha institución, aunque nunca haya llegado, en los diez años que está en ella, a comprender qué es y a qué se dedica, pese a lo cual acepta todos los ritos que se realizan allí y cumplió con todas las tareas extravagantes que le asignaron.

Sin duda, la creación de una atmósfera de lo absurdo en «La insignia» no es algo gratuito ni puramente lúdico. Además de responder a una de las corrientes estéticas que existían en el cuento peruano de la década del 50 (Cf. González Vigil 1991: 487 y 1942 1958), hay en este relato una crítica a la ausencia de sentido social, cultural o histórico en la sociedad contemporánea, en la cual los signos han llegado a cobrar una gran importancia, aunque en sí mismos carezcan de un sentido profundo o trascendente para el ser humano. Además los sucesos se realizan en una ciudad no identificada y ello contribuye a darle al relato un aire de cosmopolitismo que es un rasgo relativamente novedoso en la producción cuentística de Ribeyro de esos años (Cf. González Montes 2005: 93 y sgts.).

«Doblaje» es otro relato que enriquece el universo narrativo del autor, pues plantea con más audacia y originalidad la presencia de lo fantástico en la realidad. La anécdota, en este caso, no se desencadena a partir del azar, sino como corolario de cierta idea que el narrador enuncia con énfasis, y que en sí misma es un reto. Según dicha idea: «Todos tenemos un doble que vive en las antípodas. Pero encontrarlo es muy difícil porque los dobles tienden siempre a efectuar el movimiento contrario».

Como hemos realizado un análisis exhaustivo del relato al cual remitimos (Cf. González Montes 103 y sgts.) en estas líneas examinaremos el sentido de la afirmación antes trascrita para destacar su carácter de hipótesis sugestiva que el relato se encarga de comprobar de modo verosímil y convincente para el lector. Lo primero que habría que destacar es que este enunciado no es una verdad científica sino un «saber» propio del esoterismo, como lo reconoce el narrador de «Doblaje». Y el esoterismo se refiere a un «conjunto de conocimientos, enseñanzas, prácticas o ritos de una corriente religiosa o filosófica, que son secretos, incomprensible o de difícil acceso y que se transmiten únicamente a una minoría selecta denominada iniciados, por lo que no son conocidos por los profanos». ${ }^{14}$

En cuanto a la primera parte de la frase esotérica, la que asevera que «todos tenemos un doble», ella ha devenido en un creencia aceptada no solo en el ámbito de lo esotérico sino en el mundo de la realidad común, pues todos participan de su certeza y su significación

14 Cf. Wikipedia. Enciclopedia libre. Consultada el 17 de enero de 2009. 
alude al parecido físico existente entre, por lo menos, dos personas. Como la palabra «doble» posee muchas acepciones, recurriremos a un término equivalente pero de uso restringido, que da una idea del contenido específico que queremos establecer. Dicho término es «sosías» y con él nos referimos a «una persona que tiene parecido con otra hasta el punto de poder ser confundida con ella» (DRAE 2001: t. 9, 1423). ${ }^{15}$

El aspecto espacial también es relevante porque un sosías, según lo que se cree, nunca vive cerca del suyo, sino exactamente en el lugar opuesto al que habita el primero, porque eso es lo que significa las antípodas. ${ }^{16} \mathrm{~A}$ su vez, la segunda oración establece un rasgo que dificultaría el que un sosías puede conocer directamente o en persona al suyo, pues como se señala: «los dobles tienden siempre a efectuar el movimiento contrario»; lo que no impediría que otra persona sí pudiera conocer a ambos sosías y dar fe de ello. Por otro lado, con los avances tecnológicos, en especial la vía satélite y la televisión, sí sería posible que los dos dobles se vean a través de la pantalla televisiva, aunque nunca puedan estar el uno cerca del otro, por lo que establece el principio.

Todos estos supuestos funcionan como una suerte de verosímil del texto y Ribeyro los respeta escrupulosamente y convierte a estas leyes especiales en elementos constitutivos de la lógica de «Doblaje» en tanto relato fantástico, con las características propias de su peculiar estética. ${ }^{17}$ El resultado es un logrado texto que persuade al lector y lo deja con una inquietud respecto de esta curiosa historia que, como hemos dicho, es una comprobación convincente de aquello que se enuncia en el principio esotérico elegido por el narrador para someterlo a una demostración narrativa.

Pero «Doblaje» no solo es importante porque muestra la competencia de Ribeyro para elaborar un relato fantástico, sino porque introduce ejes temáticos nuevos que

15 En un blog encontramos una definición escrita en una norma coloquial: "es una persona que se parece extraordinariamente a ti, sin ser tu pariente consanguíneo. Tanto se parece, que hasta puede pasar por tu hermano o por ti mismo". En Martini Doble. El blog. <http://martinidoble.com>. Consultado el 17 de enero de 2009.

16 Antípoda o antípodas «es el lugar de la superficie terrestre diametralmente opuesto a otro lado, es decir, el más alejado. Según la RAE, un antípoda es aquel habitante del globo terrestre que, respecto a otro, mora en un lugar diametralmente opuesto». Wikipedia. La enciclopedia libre, consultada el 17 de enero de 2009.

17 Siempre resulta difícil definir qué es un relato fantástico, porque además existe una variedad dentro de ellos. Por ejemplo, Ribeyro practica un tipo de fantasía muy sutil, parecida al de autores como Borges y Cortázar. A propósito de ello véase un trabajo de Alejandro Danino en el que analiza tres textos fantásticos: «Borges y yo», de Jorge Luis Borges; «Continuidad de los parques» y «Casa tomada», de Julio Cortázar (Consultado en línea el 17 de enero de 2009). 
adquirirán una mayor relevancia en los libros que publicará el autor en los años posteriores a sus dos primeros volúmenes de la década del 50, que son los que hemos considerado en esta aproximación a su arte narrativo. Uno de estos temas es, por ejemplo, el del espacio cosmopolita en que se desarrollan los hechos (Londres y Sydney), y el personaje también participa de este rasgo. Además, el motivo del viaje también es novedoso porque hasta antes de este relato, los personajes se mueven en espacios cerrados y únicos (una habitación) o hacen viajes muy breves. En cambio en «Doblaje», el narrador viaja desde Londres hasta Sydney y de aquí retorna a Londres; a su vez, su sosia vuela desde Sydney hasta Londres y luego regresa a Sydney, en cumplimiento del movimiento contrario que realizan los dobles; pero no impide mostrar elementos de aquellos lugares que los personajes recorren.

Por último, habría que indicar que los protagonistas de los relatos fantásticos ya no viven solo experiencias ligadas a la lucha por la supervivencia ni pertenecen a sectores sociales muy desfavorecidos económicamente. Por el contrario, estos seres se ubican en los sectores medios y su relativa solvencia material les permite dedicarse a actividades intelectuales (el esoterismo) o efectuar viajes a lugares del extranjero.

Un último ejemplo de un relato con estas y algunas otras características afines es «El libro en blanco». Pero como hemos indicado, este texto no formó parte de la edición original del libro de 1958, sino que se incorporó en la edición de Cuentos completos de 1994, pues Ribeyro consigna al final del cuento el año 1993 como su fecha de escritura.

Por su temática se vincula al tema central de nuestra tesis, pues el protagonista es un escritor que vive una curiosa experiencia vinculada al libro como objeto, pero hay que recordar que su aparición es posterior a la data de la primera edición de Solo para fumadores, el libro en el que el tema de lo literario asume un protagonismo peculiar, que es lo que examinamos en estas páginas.

También lo hemos analizado con detalle en un trabajo nuestro ya citado (Cf. González Montes 2005: 110 y sgts.); por ello, solo incluiremos algunas de las ideas pertinentes para destacar su calidad. En cuanto al espacio que sirve de escenario al desarrollo de los sucesos, cabe subrayar que Ribeyro eligió París, ciudad muy importante en su vida real y en su obra narrativa, como lo atestiguan su Diario personal (La tentación del fracaso) y los varios cuentos ambientados en la Ciudad Luz, incluidos en algunos de los libros que el autor dio a la publicidad a partir de la década del $70 .{ }^{18}$ De otro lado, es comparable a «La insignia» porque,

18 Varios de los cuentos de su libro Los cautivos (1972) tienen como escenario la ciudad de París; entre ellos: 
en ambos textos, las extrañas acciones que viven los protagonistas se desencadenan desde el momento en que aquellos entran en posesión de sendos objetos: una insignia y un libro. La diferencia radicaría en que el primer objeto es encontrado por el narrador de modo casual y pasa a ser de su propiedad por su propia decisión. En cambio, el libro llega a manos del otro narrador gracias al obsequio que le hace una amiga en reconocimiento a la condición de escritor del protagonista.

Este emplea el recurso de la transferencia constante de propiedad del objeto para llegar a probar, a través de los hechos, el poder maléfico que ostenta el libro. Pero este poder es mostrado de modo muy especial, pues a partir del momento en que dicho objeto deja de ser de Francesca y pasa a manos de su amigo el escritor, este señala que en el lapso en que ha sido propietario del libro (un año), su situación laboral y sentimental ha desmejorado mucho; como también había ocurrido antes con Francesca cuando esta guardaba en uno de sus estantes el libro de marras. En cambio, después de haberlo regalado su situación mejora.

Por circunstancias que el relato detalla observamos que el objeto deja de pertenecer al escritor innominado y pasa a ser propiedad de otro escritor, amigo del primero, y cuyo nombre es Álvaro Chocano. Este también sufre lo que antes habían padecido la primera y el segundo propietario, es decir, el que cuenta esta curiosa historia; incluso Álvaro después de caer enfermo, agravó y murió. Después de este suceso, Francesca y el narrador se reencontraron y constataron que ambos pasaban por un buen momento, en especial en lo sentimental y hasta bromearon con la posibilidad de celebrar en una misma casa sus respectivos matrimonios.

El maléfico libro en blanco vuelve a entrar en la vida del personaje-narrador (sin que este lo sepa), pues la viuda de su difunto amigo Álvaro Chocano, cumpliendo un deseo del ausente, le entregó cuatro cajas cerradas que contenían «sus poemas inéditos y parte de su biblioteca». El narrador recibió dicho «presente griego» y no tuvo oportunidad de revisar el contenido, pero a los pocos días de recibir esos paquetes su suerte se tornó muy adversa, como ya le había ocurrido antes.

Sumido en la indigencia económica y en la carencia afectiva (su pareja lo volvió a dejar), el protagonista pasaba su tiempo escribiendo artículos que luego ofrecía sin éxito y ordenando sus papeles. En esas circunstancias se le ocurrió abrir las cajas cerradas y allí buscando el poema inédito de su amigo volvió a encontrar el famoso «libro en blanco»; buscó

«La primera nevada», «La estación del diablo amarillo», «Nada que hacer. Monsieur Baruch», etc. Su célebre relato "Juventud en la otra ribera» también se desarrolla en París. 
en sus páginas el texto poético pero descubrió que seguía impoluto. No le quedó otra opción que poner el libro en los estantes de su biblioteca.

Empero, el narrador aún no había percibido la relación que existía entre la posesión del objeto y la mala suerte de su poseedor. Poco después recibió un mensaje de su amiga Francesca en el que le anunciaba que se volvía a casar con su ex marido y lo invitaba a asistir a la ceremonia. El narrador pensó en el regalo de bodas y como no tenía ni trabajo ni dinero decidió obsequiarle el «libro en blanco» y le dio a este presente un sentido de restitución pues ese objeto había sido de ella y le costó desprenderse de él. Lo que no calculó el oferente es que Francesca le devolviera el libro, con un mensaje que decía: «Lo regalado no se devuelve».

Sorprendido por la respuesta de su amigo y en posesión, otra vez, del enigmático objeto, el narrador lo hojea de pasada y al hacerlo descubre un breve poema de la autoría de Álvaro Chocano, sin duda. Y en ese texto se revela el secreto del libro descubierto por el difunto escritor y dirigido a su amigo. Le dice que es un «objeto réprobo maléfico» del que hay que librarse de una maldición, pues "contiene todas las penas del mundo», y añade que «un libro no escrito (puede) conducirte a la muerte».

Espantado por la dura revelación del secreto, el narrador se apura en deshacerse del objeto maléfico, pero no se lo transfiere a otra persona sino que lo arroja en un parque cercano a su casa. Y a los pocos días (de paseo por el parque en compañía de un amigo) comprobó que el rosedal donde había arrojado el libro solo era un arbusto de ramas secas con pétalos marchitos. Con ello se confirma el poder destructor del objeto que no solo afecta a los humanos sino a la naturaleza.

Por el carácter de la historia contada puede calificarse a «El libro en blanco» como un relato fantástico, aunque con una fantasía muy sutil y convincente pues el narrador ha sabido probar con verosimilitud el poder especial de este objeto. La interrogante que plantea Ribeyro es por qué el libro, en este caso, está asociado a lo maléfico, cuando, por lo general, se le vincula a lo positivo. ¿Puede haber libros de por sí réprobos? La respuesta que insinúa el relato es que solo tienen esa condición aquellos que permanecen en blanco, que son una metáfora de la esterilidad de un escritor que no es capaz de romper el maleficio de la página en blanco y renuncia a explotar la capacidad creativa de la escritura. Si uno de los poseedores del libro hubiera acometido la tarea de plasmar una obra completa en las páginas impolutas del volumen citado, el maleficio habría terminado. ${ }^{19}$

19 El tema de la esterilidad o de la dificultad del escritor para afrontar hasta las últimas consecuencias el reto 
Como ya habíamos indicado, este relato también pertenece al tema de lo literario en la obra cuentística de Ribeyro, pero como señalábamos, aunque haya sido incorporado al libro Cuentos de circunstancias, su escritura es muy posterior a la fecha de la primera edición de dicho libro y recién se le agrega en la edición de Cuentos completos de 1993, en la que el volumen de 1958 experimenta algunas modificaciones en cuanto al reordenamiento de los textos y a la inclusión de algunos nuevos («La molicie» $\mathrm{y}$ «El libro en blanco») (Cf. González Montes 2005: 92). Lo que sí cabe agregar es que el relato que acabamos de analizar es comparable con el texto «El amor a los libros», también de Ribeyro y en el que este establece que «existe un amor físico a los libros muy diferente al amor intelectual por la lectura» (Ribeyro 1976: 45). ${ }^{20}$

Establecida esta sutil diferencia, cabría entonces indicar que en «El libro en blanco» se expresa sobre todo el amor físico porque el narrador y protagonista de la historia se enamora del libro de su amiga Francesca no por su contenido sin por su belleza física, por su aspecto artístico. Y quizá por ello se resiste a escribir en él y prefiere ubicarlo en su estante como un objeto de contemplación, digno de admiración. También su amigo Álvaro sucumbe a la belleza del objeto y apenas es capaz de escribir unas breves líneas en las páginas en blanco del volumen. Queda en el misterio el modo en que este personaje descubre el poder maléfico del objeto; lo importante, en todo caso, es que lo trasmite mediante la escritura y de esa manera evita que el libro siga haciendo estragos entre sus eventuales poseedores.

de crear una obra literaria también está presente, en alguna medida, en el relato "Ausente por tiempo indefinido» que analizamos más adelante.

20 Apareció primero en el diario limeño El Comercio, el 14 de julio de 1957. 


\section{Bibliografía}

ELMORE, Peter

2002 El perfil de la palabra. La obra de Julio Ramón Ribeyro. Lima: Fondo Editorial de la Pontificia Universidad Católica del Perú.

EsLava, Jorge

1993 «La adolescencia en esta ribera». En La Casa de Cartón. Revista de Cultura, N. 1, año II, Época. Lima.

González Montes, Antonio

2005 Algunas técnicas narrativas en la cuentística de Julio Ramón Ribeyro (La palabra del mudo. Tomo I). Lima: IDIC, Universidad de Lima.

1993 «La narrativa de Vallejo». En González Vigil, Ricardo (ed.). Intensidad y altura de César Vallejo. Lima: Fondo Editorial de la Pontificia Universidad Católica del Perú.

GonZÁlez VigIL, Ricardo

1991 El cuento peruano: 1942-1958. Lima: Petróleos del Perú.

López Maguiña, Santiago

1991 «Los espejismo de la verdad. Ensayo de interpretación semiótica de "La botella de chicha” de Julio Ramón Ribeyro». Lienzo. Revista de la universidad de Lima, N. 11, julio.

MinARDi, Giovanna

2002 La cuentística de Julio Ramón Ribeyro. Lima: Banco Central de Reserva del Perú-La Casa de Cartón.

Reis, Carlos y Ana Cristina M. Lopes

1995 Diccionario de Narratología. Salamanca: Ediciones Colegio de España. 
Ribeyro, Julio Ramón

1994 La palabra del mudo. Cuentos 1952 /1993. Tomo II. Lima: Jaime Campodónico Editor.

1976 La caza sutil. Lima: Milla Batres.

1958 Cuentos de circunstancias. Lima: Nuevos Rumbos.

VARgas Llosa, Mario

1997 Cartas a un novelista. Barcelona: Editorial Ariel. 